\title{
Are U.S. Corn and Soybeans Becoming More Drought Tolerant?
}

\author{
Tian Yu and Bruce A. Babcock
}

Working Paper 09-WP 500

October 2009

\author{
Center for Agricultural and Rural Development \\ lowa State University \\ Ames, lowa 50011-1070 \\ www.card.iastate.edu
}

Tian Yu is a graduate research assistant and Bruce Babcock is a professor and director, Center for Agricultural and Rural Development; lowa State University.

This paper is available online on the CARD Web site: www.card.iastate.edu. Permission is granted to excerpt or quote this information with appropriate attribution to the authors.

Questions or comments about the contents of this paper should be directed to Bruce Babcock, 578 Heady Hall, lowa State University, Ames, IA 50011-1070; Ph: (515) 294-6785; Fax: (515) 294-6336; E-mail: babcock@iastate.edu. 


\title{
Are U.S. Corn and Soybeans Becoming More Drought Tolerant?
}

\begin{abstract}
An objective drought index that measures the dry and hot conditions adversely affecting crop yields is used in a regression analysis to test whether corn and soybeans have become more drought tolerant. Results indicate that corn yield losses from a drought of a given severity, whether measured in quantity terms or as a percentage of mean yield, have decreased over time. The null hypothesis that the absolute level of soybean yield losses due to drought has not changed cannot be rejected. But soybean yield losses in percentage terms have decreased over time. Because drought is the primary cause of yield loss in the U.S. crop insurance program and because U.S. crop insurance rates assume that percentage yield losses are constant over time, these results indicate that U.S. crop insurance rates in the Corn Belt are too high.
\end{abstract}

Key words: corn, crop insurance rates, drought tolerance, soybean, yield risk Much effort is being devoted to increasing the drought tolerance of crops. The first results of this effort are expected to be released in new corn hybrids (Agriculture Online 2009; Monsanto 2009b). But claims of increased drought resistance in corn hybrids are already being made (Barrionuevo and Bradsher 2005; Monsanto 2009a). The argument is that better management ability combined with more vigorous corn hybrids lessens yield losses from drought. One implication of increasing drought tolerance would be that U.S. crop insurance rates are too high. Most crop insurance rating methods are based on the assumption that the coefficient of variation of yields is constant over time (Paulson and Babcock 2008; Woodard, Sherrick, and Schnitkey 2009). Such an assumption would be 
difficult to defend if the degree of drought tolerance is changing because drought is the primary source of loss in the U.S. crop insurance program.

One difficulty in determining whether crops are becoming less susceptible to drought using only yield data over time is that the incidence of major U.S. droughts is not constant over time in any region. For example, in the Corn Belt, a multi-state drought has not occurred since 1988 whereas multiple droughts have occurred in Great Plains states since 2000. A model that only looked at how crop losses have varied over time would conclude that losses have declined in the Corn Belt but not in Great Plains states. This would then lead one to the possibly spurious conclusion that yield risk has been declining in the Corn Belt and increasing or staying the same in Great Plains states. This difference in the incidence of drought over time could explain recent findings by Woodard et al. (2008) that crop insurance rates in U.S. Corn Belt states are too high.

In this study we use county yields in major Corn Belt states to test the hypothesis that U.S. corn and soybeans are becoming more drought tolerant over time. Because corn and soybeans are grown by the same managers, inclusion of both crops allows for some insight into whether better management or better hybrids is responsible for any finding that yields have become less susceptible to drought. In testing the hypothesis of increasing drought tolerance we avoid spurious correlation by controlling for the incidence of drought over time and space by constructing an objective measure of drought severity. We measure the impact of drought on yield both in quantity (bushels) and percentage (of mean yield) terms. Our results indicate that corn has indeed become more drought tolerant since 1980 both in terms of bushels and percentage losses. In contrast, soybeans has become more drought tolerant only in terms of percentage of yield lost, but not in terms of the absolute number of bushels lost to drought. Our findings suggest a need to modify assumptions and methods that underlie current crop insurance rates. We demonstrate that such modifications could lead to substantial reductions in both corn and soybean crop insurance rates. 


\section{Crop Yield and the Drought Index}

Abnormally hot and dry weather in growing seasons is detrimental to crop yields in the U.S. Corn Belt (O’Brien, Hayenga, and Babcock 1996). Thompson (1986) found that coolerthan-normal, wetter-than-normal, and less-variable-than-normal weather conditions in July and August were reasons for high corn yields in the Corn Belt. Figure 1 shows a scatter plot of corn yields in Clay County in Illinois, with superimposed trends. Dots represent crop yields in normal years, and squares with year labels represent crop yields in drought years. The dashed line represents a linear trend of all corn yields in the sample, while the solid line presents a linear trend of a subsample excluding corn yields in these drought years. Corn yields in drought years were significantly lower than yields in normal years, which indicates that risk of yield loss is much higher in drought years than under normal growing conditions. To measure yield risk, the traditional two-stage method is first to fit a trend line to crop yields (the dashed line), and then to measure the deviation of crop yield from the trend line (the distance from the dots and squares to the dashed line) as a proxy of risk (Paulson and Babcock 2008). Since there were more incidents of severe droughts in the first half of the sample (in 1980, 1983, 1988, 1991) than in the second half (only in 2002), and severe droughts led to large yield losses, the two-stage method is likely to conclude that yield risk in the first half of the sample is larger than in the second half. But if the temporal patterns of past droughts had been different, with more droughts in the latter part of the sample, then it would be less clear if yield risk indeed decreased. The temporal distribution of droughts could also affect trend estimation in the first step of the two-stage method. For example, in the case of Clay County, elimination of the drought years increased the slope of the trend line. This example illustrates the importance of measuring and controlling for drought in estimating yield trends and yield risk, especially when there are several severe droughts unevenly distributed over time. While changing growing conditions could mistakenly be identified as a change in yield risk, improved drought tolerance is a real 
source of reducing yield risk. Once droughts have been measured and any change in the degree of drought tolerance quantified, we can then measure possible changes in yield risk due to increasing (or decreasing) drought tolerance.

\section{Data}

In this study, we relate crop yields to drought measures. The data used include county-level corn and soybean yields and weather information in Iowa, Illinois, and Indiana from 1980 to 2008. County-level production and planted acreage data were collected from the National Agricultural Statistics Service (NASS) to calculate yield per planted acre. Observations with zero production or missing acreage data were deleted. To focus our attention on major production areas, only counties with yield data in all years from 1980 to 2008 were kept. ${ }^{1}$

Temperature and rainfall information were collected from the National Oceanic and Atmospheric Administration (NOAA). Four weather measures were used in our analysis: cooling degree days (CLDD), number of days with greater than or equal to 0.1 inch precipitation (DP01), monthly mean temperature (MNTM), and total monthly precipitation (TPCP). Monthly records of the four measures from June to August were summed up as a growing season total. For counties with multiple weather stations, we took the simple averages of weather records from all weather stations located in the county to obtain county-level weather data. For each year, yields were matched with county-level weather data. Among them, less than $5 \%$ of observations did not have matching records for one or more of the four weather measures. Observations without weather records necessary to calculate the drought index were treated as missing values and were excluded from the regression analysis.

\section{Drought Index}

Based on county-level rainfall and temperature data, we constructed an objective drought index. This index should capture the presence of both unusually hot and unusually dry con- 
ditions. Severity of hotness (dryness) can be measured by the degree to which temperature (rainfall) departs from the historical normal. The product of the number of standard deviations that the temperature measure reaches above the mean and the rainfall measure falls below the mean reflects the dual impacts of hotness and dryness. The higher (lower) the temperature (rainfall) measure is above (below) the mean, the larger will be the resulting drought index. Formally, the drought index $(D I)$ is defined as

where Temp ${ }^{\text {Stand }}$ and Rain ${ }^{\text {Stand }}$ denote the standardized temperature measure and the standardized rainfall measure, respectively. Subscripts $i$ and $t$ denote county and year. Standardized variables are calculated by subtracting county means from each observation and then dividing by the county-level standard deviations. The standardizing procedure scales the drought index so that it is comparable across counties and over time. ${ }^{2}$

As described in the previous section, we have the sum of monthly records from June to August for two temperature measures (CLDD and MNTM) and two rainfall measures (TPCP and DP01). Monthly mean temperature reflects the average level of temperature but reveals nothing about the distribution. The cooling degree days measure sums up degrees above $65^{\circ} \mathrm{F}$ on a daily basis. It contains more information about the right tail of the distribution and thus is preferable for construction of a drought index. Rainfall measures include an accumulative measure, the total precipitation, and a frequency measure, the number of days with greater than or equal to 0.1 inches precipitation (DP01). DP01 has its merit in identifying prolonged dry spells. For example, fewer than 10 days with more than 0.1 inches of rain out of the total of 180 days indicates that a dry condition persists for most of the growing season. However, other than for extremely small numbers, DP01 does not differentiate between dry and wet growing conditions as well as TPCP in general. For these reasons, we settled on a drought index calculated from CLDD and TPCP: ${ }^{3}$

$$
D I=\left[-\max \left(0, C L D D^{\text {Stand }}\right)\right] \times\left[\min \left(0, T P C P^{\text {Stand }}\right)\right] .
$$


There are three advantages associated with the drought index. First of all, it is constructed from annual county-level weather data, which, compared with state- or country-level aggregates, contains localized weather information more relevant to county yields. Secondly, this index provides information on the top two yield loss causes for corn and soybeans in the Corn Belt - excess heat and lack of moisture. A single index instead of multiple weather variables provides us an easy way to assess the impact of the main weather factors. Finally, as expected, the drought index is correlated with yield deviations, and it also identifies major drought years. To illustrate, figure 2 plots relative corn yield deviations against the drought index for counties in Illinois in major drought years: 1983, 1988, 1991, 2002, and 2005. ${ }^{4}$ Clearly the data in figure 2 exhibit both a strong negative relationship between yield deviation and the level of the drought index as well as substantial sampling error. One source of sampling error is that soil moisture prior to drought is not incorporated because of lack of data. Under the same severity of drought, crop yields in counties with higher pre-drought soil moisture levels are likely to incur smaller yield losses.

\section{Data Selection}

Corn and soybean yields in Iowa, Illinois, and Indiana are matched with drought indices representing growing season dry/hot conditions in the same county and year of the crop yield. Summary statistics of the drought index are presented in table 1. The drought index ranges from zero to six, with zero representing growing season temperature lower than average and/or rainfall greater than average. Table 2 shows the distribution of droughts of different severity levels across states and in each decade. Note that incidents of severe droughts decreased substantially in the 1990 s and since 2000 relative to the 1980 s in all three states. In Iowa, the number of county droughts with a drought index between 1 and 2 just in the 1980s is almost 50\% greater than the number of droughts from 1990 to 2008. And there has been only one drought with a drought index greater than 2.0 since 1990 in Iowa. To accurately measure whether there has been an increase in drought tolerance over 
time requires observations of yields in drought years throughout the sample. We would not be able to quantify change of drought tolerance if there were no severe drought incidents in later periods. Thus, for the analysis presented in the following sections, we keep only those counties in crop reporting districts $(\mathrm{CRD})^{5}$ that have at least two drought incidents with an index larger than 2.0 or at least three drought incidents with an index larger than 1.5 since 2000. These selection criteria leave us with counties in five CRDs in Indiana and six CRDs in Illinois. The total number of counties in the sample is 96 . Note that we do not include any Iowa counties in the analysis because there simply have not been any serious droughts in Iowa since 1990. A histogram of drought indices in the 11 CRDs is presented in figure 3.

\section{Drought Tolerance and Yield Risk}

There are different approaches that could be taken to see if there has been an increase in drought tolerance over time using the crop yield data and matched drought indices. One way is to compare yield losses in drought years in the first decade with yield losses in the last decade for droughts of similar magnitude. We classify droughts into categories of degrees of severity according to indices falling within ranges $(0, .5],(.5,1], \ldots,(2.5,3]$, $(3,6]$. Mean yield losses across counties in each drought category from 1980 to 1989 are compared to mean yield losses in the corresponding category from 2000 to 2008. Figure 4 shows bar charts of crop losses in each drought category with the mean of drought indices in each category on the $\mathrm{x}$-axis and mean of crop losses on the $\mathrm{y}$-axis. As shown, in each drought category, corn yield losses measured in both bushels per acre and in percentage of mean yield declined in 2000-2008 compared with the 1980s. This suggests that corn yields have indeed become less susceptible to the effects of drought. The situation for soybeans seems less strong. No clear-cut conclusion can be drawn regarding changes in losses in soybean bushels. Soybean percentage losses decreased in the latter period, but to a lesser degree than did corn. 
The bar charts in figure 4 also show that the relationship between crop losses and the drought index is probably non-linear. The marginal impact of drought on yield seems to decline with drought severity. This pattern suggests inclusion of a quadratic term of the drought index in the regression equation of crop yield that follows.

\section{Modeling Crop Yield with the Drought Index}

The nonparametric results presented in figure 4 indicate that drought tolerance has increased for corn and perhaps for soybeans. We now turn to regression analysis to test this hypothesis and to obtain estimates of the magnitude of any effect. The model we use is a fixed-effect regression model using the panel of data consisting of county yields and matching county-level drought indices. The first regression equation we specify is as follows:

$Y_{i, t}=\beta_{\text {cons }}+\alpha_{i}+\sum_{r=1}^{R} \gamma_{r}\left(C R D_{r} \times T\right)+\beta_{d i} D I_{i, t}+\beta_{d i t} D I T_{i, t}+\beta_{d i s q} D I S Q_{i, t}+\beta_{d i s q t} D I S Q T_{i, t}+\varepsilon_{i, t}$.

Subscripts $t, i$, and $r$ denote time, county, and crop reporting districts, respectively. $Y$ denotes crop yield. $T$ is a trend variable, which takes values 0 to 28 for years 1980 to 2008 . $D I$ is the drought index. DIT, DISQ, and DISQT are variables defined as follows: DIT = $D I \times T, D I S Q=D I \times D I, D I S Q T=D I \times D I \times T . C R D_{r}, r=1,2, \ldots, R$, denote regional dummy variables. $\mathrm{R}$ is the number of crop reporting districts. $C R D_{r}=1$, if the yield observation is from crop reporting district $r$, and $C R D_{r}=0$ otherwise. $\alpha_{i}$ is the countylevel fixed-effect parameter. Without constraints, the fixed-effect parameter $\alpha_{i}$ and the coefficient of a time-invariant variable (the constant term) $\beta_{\text {cons }}$ are not identified. Without loss of generality, we assume that $\sum_{i} \alpha_{i}=0$. In this case, $\beta_{\text {cons }}$ is the average intercept term, with $\alpha_{i}$ being each county's departures from the average. As usual, the error term $\varepsilon_{i, t}$ is assumed to be mean zero over $i$ and $t . \alpha, \beta$, and $\gamma$ are parameters to be estimated.

The yield regression model specified in (3) assumes a linear trend and explicitly ac- 
counts for the impact of drought. Crop yield consists of three parts: a deterministic trend yield $\left(\beta_{\text {cons }}+\alpha_{i}+\sum_{r=1}^{R} \gamma_{r}\left(C R D_{r} \times T\right)\right)$, a drought-driven deviation $\left(\beta_{d i} D I_{i, t}+\beta_{d i t} D I T_{i, t}+\right.$ $\beta_{d i s q} D I S Q_{i, t}+\beta_{\text {disqt }} D I S Q T_{i, t}$ ), and the residual $\varepsilon_{i, t}$. The linear trend has a county-specific intercept term $\left(\beta_{\text {cons }}+\alpha_{i}\right)$ and a slope $\left(\sum_{r=1}^{R} \gamma_{r} C R D_{r}\right)$, which varies across crop reporting districts. Counties located in crop reporting district $z$ have a common trend slope $\gamma_{z}$, which differs from counties in another crop reporting district, say $w$, their trend slope being $\gamma_{w}$. The drought deviation component depends on the drought index, a quadratic term of the drought index and time. Including the quadratic terms DISQ and DISQT makes the model more flexible in that marginal effects of drought could vary for different drought severities. The interaction terms DIT and DISQT capture possible changes in drought impact over time. Since drought incidents are random, the drought-driven deviation allows us to explicitly estimate a part of yield risk that is caused by adverse weather. Other random factors are modeled by the residual term $\varepsilon_{i, t}$. This specification allows for a straightforward test of whether yield loss measured in bushels per acre has varied over time.

The second regression model includes an exponential trend:

$\ln \left(Y_{i, t}\right)=b_{\text {cons }}+a_{i}+\sum_{r=1}^{R} c_{r}\left(C R D_{r} \times T\right)+b_{d i} D I_{i, t}+b_{d i t} D I T_{i, t}+b_{d i s q} D I S Q_{i, t}+b_{d i s q t} D I S Q T_{i, t}+e_{i, t}$.

The regression equation (4) appears in a log-linear form with the same right-hand side as in the linear model (3). The log-linear model has a percentage change in crop yield on the lefthand side. Here, $a$ 's, $b$ 's, and $c$ 's are parameters to be estimated. This specification allows for a straightforward test of whether percentage yield loss due to drought has changed over time.

In models (3) and (4), parameters to characterize crop drought tolerance, $\beta_{d i}, \beta_{d i t}, \beta_{d i s q}$, $\beta_{d i s q t}, b_{d i}, b_{d i t}, b_{d i s q}, b_{d i s q}$, are not region specific. We can allow these parameters to vary across CRDs by introducing products of regional dummies and the drought measures just as we did with the trend slope in equations (3) and (4). Specifically, CRD-specific models 
are

$$
\begin{aligned}
Y_{i, t}= & \beta_{\text {cons }}+\alpha_{i}+\sum_{r=1}^{R} \gamma_{r}\left(C R D_{r} \times T\right) \\
& +\sum_{r=1}^{R} \beta_{d i}^{r}\left(C R D_{r} \times D I_{i, t}\right)+\sum_{r=1}^{R} \beta_{d i t}^{r}\left(C R D_{r} \times D I T_{i, t}\right) \\
& +\sum_{r=1}^{R} \beta_{d i s q}^{r}\left(C R D_{r} \times D I S Q_{i, t}\right)+\sum_{r=1}^{R} \beta_{d i s q t}^{r}\left(C R D_{r} \times D I S Q T_{i, t}\right)+\varepsilon_{i, t} \\
\ln \left(Y_{i, t}\right)= & b_{\text {cons }}+a_{i}+\sum_{r=1}^{R} c_{r}\left(C R D_{r} \times T\right) \\
& +\sum_{r=1}^{R} b_{d i}^{r}\left(C R D_{r} \times D I_{i, t}\right)+\sum_{r=1}^{R} b_{d i t}^{r}\left(C R D_{r} \times D I T_{i, t}\right) \\
& +\sum_{r=1}^{R} b_{d i s q}^{r}\left(C R D_{r} \times D I S Q_{i, t}\right)+\sum_{r=1}^{R} b_{d i s q t}^{r}\left(C R D_{r} \times D I S Q T_{i, t}\right)+e_{i, t} .
\end{aligned}
$$

In this case, all coefficients are CRD specific. Not only the trend parameters but also the drought parameters have scripts $r$, with $r=1,2, \ldots, R$. The estimated coefficients in (5) and (6) are the same with what we would get by repeatedly regressing (3) and (4) using subsamples of each CRD. The benefit of estimating (5) and (6) instead of CRD-by-CRD regressions is that we can perform F-tests to see if there are regional differences in how drought has affected yield over time.

The fixed-effect model is chosen over pooled OLS and random-effect models for two reasons. First, omitted time-invariant, county-specific factors that influence crop yield can be incorporated by the fixed-effect parameters $\alpha_{i}$. Second, $\alpha_{i}$ parameters differ among units, but for any particular unit, their value is constant in the fixed-effect model. Estimates of $\alpha$ 's are of interest to us, particularly in estimating trend yields for each county.

The residual term, a proxy of all other yield risks, could be heteroskedastic among counties and over time. If the residual is heteroskedastic, estimated $\beta$ 's are consistent but their standard errors are underestimated. To test heteroskedasticity in a fixed-effect model setting, a modified Wald test is performed after regression (Greene 2000). The null hypothesis 
that variance of residuals in all counties are equal is rejected at the $1 \%$ significance level. As suggested by Arellano (1987), a Huber/White/sandwich type variance matrix estimator

of $\hat{\beta}$ is used in the context of a fixed-effect model (which Arellano called the within-group model) to get robust standard errors. The sandwich estimator is valid in the presence of any heteroskedasticity or serial correlation in the error term, provided $\mathrm{T}$ is small relative to $\mathrm{N}$ (Wooldridge 2002). ${ }^{6}$

\section{Impact of Drought}

The aggregate regression models (3) and (4) as well as the CRD-specific regression models (5) and (6) explicitly account for the impact of drought on crop yield. With some derivation, marginal effects of drought as well as change in the crop losses from drought over time can be expressed as functions of model parameters. These expressions are derived for the aggregate models. Expressions for CRD-specific models follow by replacing the drought parameters with CRD-specific parameters.

For the linear regression model, the impact of drought on yield per acre is simply

\section{(7) Drought Deviation $\equiv \beta_{d i} D I_{i, t}+\beta_{d i t} D I T_{i, t}+\beta_{d i s q} D I S Q_{i, t}+\beta_{d i s q t} D I S Q T_{i, t}$.}

. Thus the change in drought deviation over time is

$$
\frac{\partial \text { Drought Deviation }}{\partial T}=\beta_{d i t} D I_{i, t}+\beta \text { disqtDI } I_{i, t} \times D I_{i, t} \text {. }
$$

If we constructed our drought index correctly, then the drought deviation should be negative. For a given level of drought severity, (8) will be negative if yield loss from a drought of a given severity increases over time. If yields are becoming less susceptible to drought when the yield loss is measured in bushels, then (8) will be positive.

We could also use the linear specification (3) to test whether the percentage yield loss is increasing or decreasing over time, but the test statistics for testing this hypothesis are much more straightforward using the log specification (4). The percentage change in yield 
with respect to the drought index is simply

$$
M E^{\text {relative }}=\frac{\partial \ln (Y)}{\partial D I}=\left(b_{d i}+2 b_{d i s q t} \times D I_{i, t}\right)+\left(b_{d i t}+2 b_{d i s q t} \times D I_{i, t}\right) \times T
$$

and the change in drought susceptibility over time is simply $\left(b_{d i t} D I_{i, t}+b_{d i s q t} D I_{i, t} \times D I_{i, t}\right)$.

\section{Estimation Results}

We estimate yield regression models (3), (4), (5), and (6) using panel data of corn and soybean county yields, together with county-level drought indices. Table 3 provides point estimates and robust standard errors (in brackets) of the CRD-invariant coefficients in the aggregate models (3) and (4). Table 4 provides point estimates of the CRD-specific trend coefficients $\gamma_{r}$.

Columns 2 and 4 in table 3 provide estimated drought parameters for the linear model. The $\beta_{d i}$ 's are negative and significant for both corn and soybeans, which means that the drought index indeed captures the adverse effect of drought on yield. The $\beta_{\text {disq }}$ 's are positive and significant for both crops, which means that marginal yield losses decline with drought severity. $\beta_{\text {dit }}$ is positive and significant for corn, which implies that corn is less susceptible to minor droughts in terms of bushels lost over time. $\beta_{\text {disqt }}$ is negative for corn, implying that over time, losses in corn bushels under severe droughts are not reduced as much as under minor droughts. $\beta_{\text {dit }}$ and $\beta_{\text {disqt }}$ for soybeans are both insignificant. This means that in bushel terms, there is no evidence that drought susceptibility of soybeans has changed in the past 28 years.

Columns 3 and 5 in table 3 provide estimated drought parameters for the log-linear model. The $b_{d i}$ 's are negative and significant for both crops as expected. The $b_{d i s q}$ 's are positive and significant for both crops, which means marginal percentage losses are higher under minor droughts and lower under severe droughts, in the earlier period of the sample. The $b_{d i t}$ 's are significant and positive for both crops. Both corn and soybeans are becoming less susceptible to minor droughts in percentage terms. $b_{\text {disqt }}$ is significant and negative for 
corn, implying that percentage corn yield losses are not decreasing as much under severe droughts as under minor droughts over time. $b_{\text {disqt }}$ is insignificant for soybeans implying that improvement of soybean drought tolerance measured in percentage terms is similar under minor droughts compared to severe droughts.

Regression results have implications for crop yield risk. Crop yield risk comes from multiple sources. Drought risk is one important source. Our regression models explicitly estimate crops' ability to withstand drought. If the weather conditions, particularly the distribution of drought index, remains the same over time, changes in drought tolerance translate directly into changes in drought-induced yield risk. An increasing (decreasing) drought tolerance results in decreasing (increasing) drought-induced yield risk. Based on regression results, one can test the null hypothesis that absolute (relative) yield risk induced by drought is constant over time.

Based on the linear model, the null hypothesis that absolute yield risk induced by drought is constant over time is equivalent to the annual change in bushels lost to drought being zero:

$$
H_{0}: \beta_{\text {dit }} D I+\beta_{\text {disqt }} D I \times D I=0 .
$$

Based on the log-linear model, the null hypothesis of constant relative yield risk induced by drought is equivalent to the annual change in percentage yield losses being zero:

$$
H_{0}: b_{d i t} D I+b_{d i s q t} D I \times D I=0 .
$$

Both one-sided and two-sided t-tests are conducted for null hypotheses (10) and (11). Tables 5 and 6 provide t-statistics and p-values for these tests. For corn, the null hypothesis that yield losses have not changed over time is rejected in favor of the alternative hypothesis that yield losses have declined over time. This conclusion holds whether yield loss is measured in bushels per acre or as a percentage of mean yields. For soybeans, the null hypothesis that yield losses measured in bushels per acre are constant over time cannot 
be rejected. However, the null hypothesis that percentage yield losses have not changed over time is rejected in favor of the alternative hypothesis that percentage yield losses have decreased over time.

Based on model estimates, the marginal effects of drought evaluated at drought index level 1.0 (an average drought severity level) are listed in table 7. An increase in the drought level from 1.0 to 2.0 would increase corn yield loss by 26 bushels or $32 \%$ in 1980, and by about 18 bushels or $12 \%$ in 2008 . The estimated marginal impact of increasing the drought level from 1.0 to 2.0 on soybean yields is four bushels per acre in both 1980 and 2008 . But because expected yields have increased over time, this loss represents a loss of $15 \%$ in 1980 and only $10 \%$ in 2008.

Table 8 provides point estimates of the change in annual yield losses due to droughts of different severities. Corn yield losses due to drought have decreased on an annual basis by 0.29 bushels to 0.57 bushels, or $0.63 \%$ to $1.4 \%$ each year, depending on drought severity. Estimated percentage soybean losses have decreased at a rate ranging from $0.15 \%$ per year to $0.33 \%$ per year. Although these annual changes may seem moderate, the magnitude is large when we consider the accumulated change over time. Figure 5 shows crop yield loss in 1980 and in 2008 under alternative drought severities. In 28 years, corn yield lost to drought is estimated to have decreased by about 15 bushels under moderate droughts. Accounting for the increase in trend yield, the percentage reduction in corn yields over the 28 years ranges from nearly $20 \%$ when the drought index is 0.5 to nearly $40 \%$ when the drought index is 2.0. Soybeans lost as many bushels to drought in 2008 as in 1980. In relative terms, however, the reduction in soybean losses was about $5 \%$ to $10 \%$ over the past 28 years.

To estimate possible CRD-specific drought effects, we also fit models (5) and (6) with the same panel data. Tables 9 and 10 provide point estimates of coefficients in the CRDspecific models. Note that, in general, the signs of the CRD-specific drought parameters match their counterparts in the aggregate models in table 3. For those drought parameters 
that are estimated to be significant in the aggregate model, estimates in the CRD-specific models are either significant with the same sign or insignificant. For the drought parameters estimated to be insignificant in the aggregate model, their estimates could take both positive and negative signs or be estimated as insignificant in the CRD-specific model. There is only one exception: $b_{d i t}^{r}$ for soybeans in Indiana district 80 has a different sign than $b_{d i t}$ in the aggregate model. Based on the CRD-specific estimates, we get similar results of annual changes in drought tolerance as from the aggregate models. Drought tolerance of corn measured in bushels per acre improved in four CRDs and showed no statistically significant changes in the other seven CRDs. Measured in relative terms, corn crops in all 11 CRDs are becoming less susceptible to drought over time. Measured in bushels per acre, soybean crops in four CRDs are becoming more drought tolerant, soybean crops in five CRDs are becoming less drought tolerant and soybean crops in the remaining two CRDs showed no significant changes. Measured in relative terms, soybean crops in five CRDs are more drought tolerant, the soybean crops in only one CRD is becoming more susceptible to drought, and the rest did not show significant changes. Thus, we can think of the aggregate estimation as the "average" of the CRD-specific estimation. The magnitude of the CRD-specific estimates varies across regions. Table 11 shows that F-tests of the null hypothesis that CRD-specific drought parameters in the CRD-specific model are equal is rejected. This suggests that corn and soybean yields in different CRDs could respond differently to droughts. One possible reason could be that pre-drought soil moisture differs across CRDs. Droughts of similar severity levels could lead to different degrees of crop losses in different CRDs. However, we lack the pre-drought soil moisture data to account for the differences. Another possible reason is that the CRD-specific regressions use only information within a CRD to estimate drought parameters for that CRD. Too few observations used to estimate each CRD-specific drought parameter leads to large standard errors of the estimated coefficients. Some of the insignificant estimates could be due to lack of information rather than no changes in drought tolerance. There could be substantial noise 
affecting CRD-specific regression results given the small sample size in each CRD. Thus, even the significant estimates could suffer from lack of precision. As shown in table 12, the aggregate models have smaller (better) Bayesian information criterion (BIC) values than do corresponding CRD-specific models. This suggests that the CRD-specific models are relatively overfitting. For these reasons, and because the table 3 results essentially represent the average of the Table 9 and 10 results, we rely on results of the aggregate models (3) and (4).

\section{Implications for GRP Rates}

The conclusion that the drought tolerance of corn and soybeans in Indiana and Illinois has changed over time has important implications for the U.S crop insurance program. A maintained assumption of the rating methods used to determine premium rates for both individual and area insurance products is that yields have constant relative risk over time. For example, the Group Risk Plan (GRP) is an area yield insurance program that pays indemnity whenever the actual county yield falls below the "trigger yield", which is a proportion of expected county yield. GRP premium rates are determined using a losscost ratio (LCR) methodology (Skees, Black, and Barnett 1997). Actuarial fairness of the LCR approach is based on the constant relative risk hypothesis (Paulson and Babcock 2008). In a situation of decreasing (increasing) relative risk, LCR methodology based on direct historical experiences overestimates (underestimates) premium rates. Individual yield insurance under the federal Actual Production History (APH) program is also based on an LCR method that requires constant relative risk over time (Woodard, Sherrick, and Schnitkey 2009). In light of our findings of decreasing drought-induced relative deviations

for both corn and soybeans at the county level, it is worthwhile to assess the impacts of modifying the underlying rating assumption of constant relative risk on GRP rating. To do this, we simulate actuarial fair rates for insuring drought-induced risk and compare them with the drought-related part of GRP rates. 
In the simulations two assumptions are made. First, the future probability of drought in any year is assumed to be captured by the historical probability of drought in our sample. This assumption can be relaxed if information about future distributions of drought becomes available. Second, to focus only on the drought portion of GRP rates, we assume that drought-induced yield risk can be rated separately from other sources of yield loss. Essentially, yield risk is assumed to be in an additive form of multiple independent risk factors with drought-induced risk being one major component. The actuarial fair rate simulated below is the rate that corresponds only to the drought-induced risk factor.

We simulate actuarially fair GRP rates for drought from 2010 to 2020 using the following steps. We first select a representative county. For each year from 2010 to 2020, we take the county's 29-year historical values of the drought index as the draws from the empirical distribution of drought. With these 29 drought index draws for each county, actual yields (ActYield) from 2010 to 2020 are predicted using fitted values from the regression models (3) and (4) with the estimated coefficients in table $3 .^{7}$ Expected yields $(E(Y))$ are predicted using the fitted values from regression models with the drought-index evaluated at its county mean. We fix the coverage level $(C)$ at 0.9 . Loss percentages (\%loss) are then calculated using (12) and (13).

$$
\text { oloss }_{i, t}=\max \left[\frac{\text { TrigYield }_{i, t}-\text { ActYield }_{i, t}}{\text { TrigYield }_{i, t}}, 0\right]
$$

The actuarial fair premium rate (Fair $\left.{ }^{\text {rate }}\right)$, is the rate such that expected indemnity (Indem) equals expected premium (Prem). It is derived in (14) to (16) to be the expected percentage loss.

$$
\operatorname{Prem}_{i, t}=\text { rate }_{i, t} \times \text { Liab }_{i, t}
$$




$$
E\left(\text { Indem }_{i, t}\right)=E\left(\text { Prem }_{i, t}\right) \Leftrightarrow \text { rate }_{i, t}=E\left(\text { oloss }_{i, t}\right) \Rightarrow \text { Fair }_{i, t}^{\text {rate }}=E\left(\% \text { loss }_{i, t}\right) .
$$

We take the average of simulated loss percentages to be the simulated fair rate. Two qualifications on the simulated fair rates need to be addressed. First, the fair rates are prices for insuring drought-induced yield losses only. Other sources of yield risk are not modeled in simulation. Second, only the regression-predicted drought-induced yield risk, or the "mean effect" of the drought shock, is modeled. Actual drought-induced yield fluctuations could be more volatile. Thus, the real actuarial fair rate should be higher. Nevertheless, simulated fair rates indicate prices of insuring model-implied drought risk.

GRP is a multi-peril crop insurance product. To make our simulated fair rates comparable to GRP rates, we need to calculate GRP rates including only those losses that occurred in drought years as indicated by this study's drought index. The modified GRP rating method is as follows. First, linear trends are fitted county by county to crop yields. Second, loss percentages are calculated for historical years according to (12) and (13), with fitted values of crop yield as expected yields and historical yield observations as actual yields. Finally, the GRP rate is set at the average of historical loss percentages:

$$
G R P_{i, t}^{r a t e}=\frac{\sum_{\tau=0}^{t} \% \text { loss }_{i, \tau}}{(t-0)}
$$

To calculate GRP drought year rates, only the final step differs:

$$
G R P_{i, t}^{\text {drought year rate }}=\frac{\sum_{\tau \in \mathfrak{R}} \% \text { loss }_{i, \tau}}{r_{i, t}}
$$

where $\Re$ is the set of drought years and $r$ is the number of drought years in history. Drought years are those identified by the drought index as being positive. The GRP drought year rate is the simple average of loss ratios in drought years only. It reflects loss experiences closely related to drought conditions that we used to simulate the fair rates. ${ }^{8}$

In tables 13 and 14, we list premium rates for selected counties in our sample. Column 3 lists unloaded and unsubsidized GRP premium rates in 2008..$^{9}$ Column 4 lists the GRP rates that we calculate for drought years using (18). Column 5 is the ratio of the drought-year 
GRP rate in column 4 divided by the GRP rate we calculate using (17), which indicates the percentage of GRP rate that can be accounted for by drought. The last three columns are simulated fair rates of insuring the model-implied drought risk in 2010, 2015, and 2020. There are two rows for each county. The first rows are fair rates predicted by the linear model. The second rows report rates predicted by the log-linear model. GRP drought year rates in column 4 are comparable to simulated fair rates in the last three columns in terms of insured risk.

For the Indiana and Illinois selected counties, almost all of the corn GRP rates are the result of drought and more than half of the soybean GRP rates are the result of drought. For both crops, the 2010 fair rates are lower than the GRP drought year rates, and they decline over time. The reason why they are lower in 2010 is that the GRP drought rate assumes constant relative susceptibility to drought from 1980 to 2008 whereas the reality is that both corn and soybeans have actually exhibited decreasing relative susceptibility. Simulated rates for corn decline faster than rates for soybeans because corn shows a larger improvement in drought tolerance.

\section{Conclusion}

By constructing an objective drought index and correlating to crop yields, we explicitly account for the impact of drought on crop yield. Regression results show that corn is becoming less susceptible to drought measured both by bushel loss and percentage loss. For soybeans, constant bushel loss is not rejected but the degree of drought tolerance measured in percentage term is decreasing over time. The decreasing relative susceptibility for both crops cast doubt on the LCR method used in rating crop insurance programs in the U.S. Simulations based on regression estimation results show that accounting for increased drought tolerance of corn and soybeans would have major impacts on premium rates for GRP.

That both corn and soybeans in Indiana and Illinois are more drought tolerant is some- 
what surprising because only now are the large seed companies focusing their efforts on developing drought-tolerant crops, and all of their work to date has been devoted to corn. Their past efforts at developing biotech corn seem to have paid off in an unanticipated manner by making corn hybrids better able to withstand drought conditions. But no such effort can explain increasing drought resistance in soybeans, unless herbicide-resistant soybeans are less susceptible to drought. Besides widespread adoption of biotech corn and soybeans that began in the 1990s, the other large change common to both corn and soybeans is that a greater proportion of both crops is being managed by larger and perhaps more able managers. Better management leads to more timely field operations, which could result in increasing drought tolerance. If true, then our finding of increased drought tolerance may apply to other crops for which management may have improved.

The improvements in drought tolerance that we have documented in corn and soybeans may be dwarfed in the future if in fact the seed companies are successful in their efforts to introduce genes that enable crops to withstand drought conditions. The crop insurance industry and the Risk Management Agency of USDA in particular should begin to alter the way they determine crop insurance rates so that as the new technologies come online, they will have a system that can reflect the new lower risks directly in premium rates. Indeed the Risk Management Agency has taken steps along these lines to have rates reflect new technology through their approval of the Pilot Biotechnology Endorsement which significantly reduces crop insurance premiums for farmers who plant corn hybrids that qualify for premium reduction. 


\section{Endnotes:}

${ }^{1}$ About $90 \%$ of counties have yield data in all 29 years.

${ }^{2}$ To eliminate the possibility that county means might be distorted by extreme values in the sample, we replaced simple county means with spatially smoothed county means. This spatial smoothing had minimal impacts on the results.

${ }^{3}$ We also experimented with drought indices calculated from other pairwise combinations of the four measures. They give similar regression results.

${ }^{4}$ Relative yield deviation is defined as actual county yield minus county trend yield, which is then divided by county trend yield.

${ }^{5}$ Crop reporting districts are aggregates of counties used by NASS.

${ }^{6}$ In our case, $\mathrm{T}$ equals 29 , and $\mathrm{N}$ equals 96.

${ }^{7}$ Only the drought index is drawn from its empirical distribution. The residual term of the yield regression is not included in the predicted "actual yield". This procedure essentially excludes all yield risks other than the drought-induced yield risk predicted by the regression.

${ }^{8}$ It also reflect other risk factors in drought years that the fair rates do not incorporate.

${ }^{9}$ We take the unsubsidized GRP rate listed on the RMA website and multiply by .88 to remove load. 


\section{References}

Agriculture Online. 2009. "Drought-Tolerant Corn Coming as Early as Next Year, Company Says.” http://www.agriculture.com/ag/story.jhtml?storyid=/templatedata/ag/story/ data/1247580632983.xml.

Arellano, M. 1987. "Computing Robust Standard Errors for Within-groups Estimators." Oxford Bulletin of Economics and Statistics 49:431-434.

Barrionuevo, A., and K. Bradsher. 2005. "Sometimes a Bumper Crop Is Too Much of a Good Thing." New York Times 8 Dec.

Greene, W. 2000. Econometric Analysis. Upper Saddle River, NJ: Prentice-Hall.

Monsanto. 2009a. "Drought Tolerance." http://www.monsanto.com/products/ techandsafety/fortherecord_science/2009/drought_tolerance.asp.

—. 2009b. "First-Generation Drought-Tolerant Corn." http://www.monsanto.com/ products/pipeline/drought_tolerant_corn.asp.

O’Brien, D., M. Hayenga, and B. Babcock. 1996. "Deriving Forecast Probability Distributions of Harvest-Time Corn Futures Prices.” Review of Agricultural Economics 18:167180.

Paulson, N.D., and B.A. Babcock. 2008. "Get a GRIP: Should Area Revenue Coverage Be Offered Through the Farm Bill or as a Crop Insurance Program.” Journal of Agricultural and Resource Economics 33:137-154.

Skees, J.R., J.R. Black, and B.J. Barnett. 1997. "Designing and Rating an Area Yield Crop Insurance Contract.” American Journal of Agricultural Economics 79:430-438.

Thompson, L.M. 1986. "Climatic Change, Weather Variability, and Corn Production." Agricultural Journal 78:649-653.

Woodard, J., B.J. Sherrick, and G.D. Schnitkey. 2009. “Crop Insurance Ratemaking under Trending Liabilities.” Unpublished, Working Paper, University of Illinois.

Woodard, J.D., G.D. Schnitkey, B.J. Sherrick, N. Lozano-Gracia, and L. Anselin. 2008. “A 
Spatial Econometric Analysis of Loss Experience in the U.S. Crop Insurance Program.” Unpublished, Working Paper, University of Illinois.

Wooldridge, J.M. 2002. Econometric Analysis of Cross Section and Panel Data. Cambridge MA: MIT Press. 
Table 1. Summary Statistics of Drought Index

\begin{tabular}{lllll}
\hline \hline Sample & Mean & Std. Dev. & Min & Max \\
\hline IA, IL, IN & .26 & .65 & 0 & 5.89 \\
IA, IL, IN with drought index larger than .1 & 1.04 & .94 & .10 & 5.89 \\
\hline \hline
\end{tabular}

Table 2. Distribution of Drought across States and in Each Decade

\begin{tabular}{cccc}
\hline \hline Period & $.1<D I<1$ & $1<D I<2$ & $D I>2$ \\
\hline & \multicolumn{4}{c}{ Illinois } \\
$1980-1989$ & 104 & 46 & 57 \\
$1990-1999$ & 85 & 44 & 7 \\
$2000-2008$ & 110 & 42 & 12 \\
\hline & \multicolumn{3}{c}{ Indiana } \\
$1980-1989$ & 78 & 37 & 62 \\
$1990-1999$ & 94 & 48 & 12 \\
$2000-2008$ & 52 & 35 & 19 \\
\hline & & Iowa & \\
$1980-1989$ & 128 & 62 & 83 \\
$1990-1999$ & 133 & 30 & 0 \\
$2000-2008$ & 203 & 13 & 1 \\
\hline \hline
\end{tabular}

Table 3. Point Estimates and Robust Standard Errors of CRD-Invariant Coefficients

\begin{tabular}{lllll}
\hline \hline & Corn Linear & Soybean Linear & Corn Log-Linear & Soybean Log-Linear \\
\hline \hline DI & $-40.6124^{*}$ & $-5.7361 *$ & $-0.5023^{*}$ & $-0.2157 *$ \\
& $(2.5117)$ & $(0.6667)$ & $(0.0369)$ & $(0.0251)$ \\
DIT & $0.6886^{*}$ & 0.0069 & $0.0143 *$ & $0.0035^{*}$ \\
& $(0.1480)$ & $(0.0417)$ & $(0.0018)$ & $(0.0013)$ \\
DISQ & $7.2940 *$ & $0.7048 *$ & $0.0914 *$ & $0.0322 *$ \\
& $(0.9451)$ & $(0.2531)$ & $(0.0133)$ & $(0.0095)$ \\
DISQT & $-0.2050^{*}$ & -0.0033 & $-0.0037 *$ & -0.0009 \\
& $(0.0539)$ & $(0.0154)$ & $(0.0007)$ & $(0.0005)$ \\
Constant $)$ & $104.6338^{*}$ & $34.4129 *$ & $4.6500 *$ & $3.5316 *$ \\
& $(0.4362)$ & $(0.1301)$ & $(0.0042)$ & $(0.0040)$ \\
\hline \hline
\end{tabular}

Note: Asterisk $(*)$ denotes estimates significant at $5 \%$. 
Table 4. CRD-Specific Trend Estimates $\gamma_{r}$ 's from Aggregate Models

\begin{tabular}{lcccll}
\hline \hline State & District & Corn Linear & Soybean Linear & $\begin{array}{l}\text { Corn } \\
\text { Log-Linear }\end{array}$ & $\begin{array}{l}\text { Soybean } \\
\text { Log-Linear }\end{array}$ \\
\hline IL & 10 & $2.295 *$ & $0.350 *$ & $0.016 *$ & $0.007 *$ \\
IL & 20 & $1.872 *$ & $0.288 *$ & $0.013 *$ & $0.007 *$ \\
IL & 40 & $2.246 *$ & $0.422 *$ & $0.015 *$ & $0.009 *$ \\
IL & 70 & $1.827 *$ & $0.504 *$ & $0.017 *$ & $0.014 *$ \\
IL & 80 & $1.665 *$ & $0.369 *$ & $0.016 *$ & $0.011 *$ \\
IL & 90 & $1.431 *$ & $0.388 *$ & $0.014 *$ & $0.012 *$ \\
IN & 10 & $1.832 *$ & $0.471 *$ & $0.014 *$ & $0.011 *$ \\
IN & 50 & $1.494 *$ & $0.438 *$ & $0.010 *$ & $0.010 *$ \\
IN & 60 & $1.549 *$ & $0.505 *$ & $0.012 *$ & $0.012 *$ \\
IN & 70 & $1.749 *$ & $0.517 *$ & $0.013 *$ & $0.014 *$ \\
IN & 80 & $1.239 *$ & $0.517 *$ & $0.011 *$ & $0.014 *$ \\
\hline \hline
\end{tabular}

Note: Asterisk (*) denotes estimates significant at 5\%.

Table 5. Hypothesis Testing with Drought Index Evaluated at 1

\begin{tabular}{|c|c|c|c|c|}
\hline Crop & 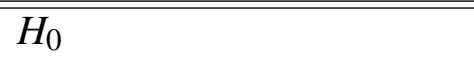 & "Test statistics & P-value & Implications \\
\hline Corn & $\begin{array}{l}\beta_{\text {dit }} D I+\beta_{\text {disqt }} D I \times D I=0 \\
\beta_{\text {dit }} D I+\beta_{\text {disqt }} D I \times D I<0\end{array}$ & $\begin{array}{l}t(95)=4.88 \\
t(95)=4.88\end{array}$ & $\begin{array}{l}.000 \\
.000\end{array}$ & $\begin{array}{l}\text { CAR rejected } \\
\text { in favor of de- } \\
\text { creasing abso- } \\
\text { lute risk }\end{array}$ \\
\hline Corn & $\begin{array}{l}b_{\text {dit }} D I+b_{\text {disqt }} D I \times D I=0 \\
b_{\text {dit }} D I+b_{\text {disqt }} D I \times D I<0\end{array}$ & $\begin{array}{l}\mathrm{t}(95)=8.90 \\
\mathrm{t}(95)=8.90\end{array}$ & $\begin{array}{l}.000 \\
.000\end{array}$ & $\begin{array}{l}\text { CRR rejected } \\
\text { in favor of de- } \\
\text { creasing rela- } \\
\text { tive risk }\end{array}$ \\
\hline Soybean & $\beta_{\text {dit }} D I+\beta_{\text {disqt }} D I \times D I=0$ & $\mathrm{t}(95)=.13$ & .897 & $\begin{array}{l}\text { Fail to reject } \\
\text { CAR }\end{array}$ \\
\hline Soybean & $\begin{array}{l}b_{\text {dit }} D I+b_{\text {disqt }} D I \times D I=0 \\
b_{\text {dit }} D I+b_{\text {disqt }} D I \times D I<0\end{array}$ & $\begin{array}{l}\mathrm{t}(95)=3.03 \\
\mathrm{t}(95)=3.03\end{array}$ & $\begin{array}{l}.002 \\
.001\end{array}$ & $\begin{array}{l}\text { CRR rejected } \\
\text { in favor of de- } \\
\text { creasing rela- } \\
\text { tive risk }\end{array}$ \\
\hline
\end{tabular}

Note: The only yield risk considered here is the drought-induced risk. 
Table 6. Hypothesis Testing with Drought Index Evaluated at 2.5

\begin{tabular}{|c|c|c|c|c|}
\hline Crop & 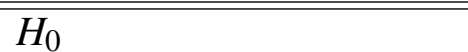 & "Test statistics & P-value & Implications \\
\hline Corn & $\begin{array}{l}\beta_{\text {dit }} D I+\beta_{\text {disqt }} D I \times D I=0 \\
\beta_{\text {dit }} D I+\beta_{\text {disqt }} D I \times D I<0\end{array}$ & $\begin{array}{l}t(95)=3.44 \\
t(95)=3.44\end{array}$ & $\begin{array}{l}.001 \\
.004\end{array}$ & $\begin{array}{l}\text { CAR rejected } \\
\text { in favor of de- } \\
\text { creasing abso- } \\
\text { lute risk }\end{array}$ \\
\hline Corn & $\begin{array}{l}b_{\text {dit }} D I+b_{\text {disqt }} D I \times D I=0 \\
b_{\text {dit }} D I+b_{\text {disqt }} D I \times D I<0\end{array}$ & $\begin{array}{l}\mathrm{t}(95)=9.07 \\
\mathrm{t}(95)=9.07\end{array}$ & $\begin{array}{l}.000 \\
.000\end{array}$ & $\begin{array}{l}\text { CRR rejected } \\
\text { in favor of de- } \\
\text { creasing rela- } \\
\text { tive risk }\end{array}$ \\
\hline Soybean & $\beta_{\text {dit }} D I+\beta_{\text {disqt }} D I \times D I=0$ & $\mathrm{t}(95)=-.08$ & .933 & $\begin{array}{l}\text { Fail to reject } \\
\text { CAR }\end{array}$ \\
\hline Soybean & $\begin{array}{l}b_{\text {dit }} D I+b_{\text {disqt }} D I \times D I=0 \\
b_{\text {dit }} D I+b_{\text {disqt }} D I \times D I<0\end{array}$ & $\begin{array}{l}\mathrm{t}(95)=2.36 \\
\mathrm{t}(95)=2.36\end{array}$ & $\begin{array}{l}.021 \\
.010\end{array}$ & $\begin{array}{l}\text { CRR rejected } \\
\text { in favor of de- } \\
\text { creasing rela- } \\
\text { tive risk }\end{array}$ \\
\hline
\end{tabular}

Note: The only yield risk considered here is the drought-induced risk.

Table 7. Marginal Effects with Drought Index Evaluated at DI = 1

\begin{tabular}{lccccccc}
\hline \hline Year & 1980 & 1985 & 1990 & 1995 & 2000 & 2005 & 2008 \\
\hline Corn Loss (bushels) & 26.02 & 24.63 & 23.24 & 21.85 & 20.45 & 19.06 & 18.23 \\
Soybean Loss (bushels) & 4.33 & 4.32 & 4.32 & 4.32 & 4.32 & 4.32 & 4.32 \\
Corn Loss (\%) Log-Linear & $32.0 \%$ & $28.5 \%$ & $25.0 \%$ & $21.5 \%$ & $18.0 \%$ & $14.5 \%$ & $12.4 \%$ \\
Soybean Loss (\%) Log-Linear & $15.1 \%$ & $14.3 \%$ & $13.5 \%$ & $12.6 \%$ & $11.8 \%$ & $11.0 \%$ & $10.5 \%$ \\
\hline \hline
\end{tabular}

Table 8. Annual Change in Crop Loss for Alternative Drought Severity Levels

\begin{tabular}{lccccc}
\hline \hline Drought Index & 0.5 & 1 & 1.5 & 2 & 2.5 \\
\hline Annual Decrease in Corn Bushel Loss & 0.29 & 0.48 & 0.57 & 0.56 & 0.44 \\
Annual Decrease in Corn Percent Loss & $0.63 \%$ & $1.07 \%$ & $1.32 \%$ & $1.40 \%$ & $1.29 \%$ \\
Annual Decrease in Soybean Bushel Loss & 0.00 & 0.00 & 0.00 & 0.00 & 0.00 \\
Annual Decrease in Soybean Percent Loss & $0.15 \%$ & $0.26 \%$ & $0.32 \%$ & $0.33 \%$ & $0.30 \%$ \\
\hline \hline
\end{tabular}


Table 9. Point Estimates of Coefficients from CRD-Specific Models

\begin{tabular}{|c|c|c|c|c|c|}
\hline State & District & Corn Linear & Soybean Linear & $\begin{array}{l}\text { Corn } \\
\text { Log-Linear }\end{array}$ & $\begin{array}{l}\text { Soybean } \\
\text { Log-Linear }\end{array}$ \\
\hline & & & Intercept & $\beta_{\text {cons }}$ & \\
\hline & & $104.8900 *$ & $34.4730 *$ & $4.6546 *$ & $3.5346 *$ \\
\hline \multicolumn{6}{|c|}{ Trend Parameter } \\
\hline IL & 10 & $2.3497 *$ & $0.3393 *$ & $0.0163 *$ & $0.0073 *$ \\
\hline IL & 20 & $1.9057 *$ & $0.2593 *$ & $0.0137 *$ & $0.0059 *$ \\
\hline IL & 40 & $2.2673 *$ & $0.3512 *$ & $0.0156 *$ & $0.0077 *$ \\
\hline IL & 70 & $1.7078 *$ & $0.4542 *$ & $0.0137 *$ & $0.0118 *$ \\
\hline IL & 80 & $1.7893 *$ & $0.4427 *$ & $0.0159 *$ & $0.0129 *$ \\
\hline IL & 90 & $1.3869 *$ & $0.4228 *$ & $0.0127 *$ & $0.0123 *$ \\
\hline IN & 10 & $1.8550 *$ & $0.4462 *$ & $0.0149 *$ & $0.0108 *$ \\
\hline IN & 50 & $1.4532 *$ & $0.4700 *$ & $0.0106 *$ & $0.0105 *$ \\
\hline IN & 60 & $1.6304 *$ & $0.5142 *$ & $0.0129 *$ & $0.0126 *$ \\
\hline IN & 70 & $1.5527 *$ & $0.5034 *$ & $0.0120 *$ & $0.0129 *$ \\
\hline IN & 80 & $1.3339 *$ & $0.5687 *$ & $0.0113 *$ & $0.0154 *$ \\
\hline \multicolumn{6}{|c|}{ Drought Parameter } \\
\hline IL & 10 & $-24.5300 *$ & 0.4016 & $-0.2606 *$ & 0.0172 \\
\hline IL & 20 & $-34.0760 *$ & $-4.9898 *$ & $-0.3283 *$ & $-0.1301 *$ \\
\hline IL & 40 & $-40.7260 *$ & $-12.9590 *$ & $-0.3920 *$ & $-0.3341 *$ \\
\hline $\mathrm{IL}$ & 70 & $-59.4110 *$ & $-12.3450 *$ & $-0.9352 *$ & $-0.5076 *$ \\
\hline IL & 80 & $-41.5350 *$ & $-5.0797 *$ & $-0.6349 *$ & $-0.2331 *$ \\
\hline IL & 90 & $-70.7350 *$ & $-11.7250 *$ & $-1.0575 *$ & $-0.5999 *$ \\
\hline IN & 10 & $-31.9900 *$ & $-7.4177 *$ & $-0.3498 *$ & $-0.2057 *$ \\
\hline IN & 50 & $-52.2970 *$ & -2.1596 & $-0.4980 *$ & -0.0742 \\
\hline IN & 60 & $-32.3670 *$ & $-4.9152 *$ & $-0.3898 *$ & $-0.1710 *$ \\
\hline IN & 70 & $-55.1150 *$ & $-8.6409 *$ & $-0.5406 *$ & $-0.3005 *$ \\
\hline IN & 80 & $-38.4830 *$ & $-6.1125 *$ & $-0.5203 *$ & $-0.2636 *$ \\
\hline \multicolumn{6}{|c|}{ Drought Parameter } \\
\hline IL & 10 & 0.0001 & 0.1004 & 0.0071 & 0.0029 \\
\hline IL & 20 & -0.1662 & 0.1039 & 0.0032 & 0.0035 \\
\hline $\mathrm{IL}$ & 40 & 0.7263 & $0.8731 *$ & $0.0143 *$ & $0.0233 *$ \\
\hline $\mathrm{IL}$ & 70 & $1.0383 *$ & 0.1975 & $0.0300 *$ & $0.0135 *$ \\
\hline $\mathrm{IL}$ & 80 & 0.3805 & $-0.3754 *$ & 0.0149 & -0.0083 \\
\hline IL & 90 & $2.0711 *$ & 0.0090 & $0.0367 *$ & $0.0109 *$ \\
\hline IN & 10 & 0.5336 & $0.4464 *$ & $0.0087 *$ & $0.0130 *$ \\
\hline IN & 50 & $1.4237 *$ & $-0.2868 *$ & $0.0153 *$ & -0.0050 \\
\hline IN & 60 & -0.0079 & $-0.1520 *$ & $0.0068 *$ & -0.0012 \\
\hline IN & 70 & $2.3829 *$ & 0.0501 & $0.0233 *$ & $0.0046 *$ \\
\hline IN & 80 & 0.0817 & $-0.3908 *$ & $0.0088 *$ & $-0.0054 *$ \\
\hline
\end{tabular}

Note: Asterisk (*) denotes estimates significant at 5\%. 
Table 10. Point Estimates of Coefficients from CRD-Specific Models - Continued

\begin{tabular}{|c|c|c|c|c|c|}
\hline State & District & Corn Linear & Soybean Linear & $\begin{array}{l}\text { Corn } \\
\text { Log-Linear }\end{array}$ & $\begin{array}{l}\text { Soybean } \\
\text { Log-Linear }\end{array}$ \\
\hline & & \multicolumn{2}{|c|}{ Drought Parameter } & $\beta_{\text {disq }}^{r}$ 's or & $b_{\text {disq }}^{r}{ }^{\prime} \mathrm{s}$ \\
\hline IL & 10 & 2.1321 & -1.1129 & 0.0146 & -0.0343 \\
\hline IL & 20 & 2.8345 & -0.3560 & -0.0024 & -0.0234 \\
\hline IL & 40 & $7.9223 *$ & $3.5543 *$ & $0.0701 *$ & $0.0868 *$ \\
\hline IL & 70 & $12.1130 *$ & $2.2724 *$ & $0.2197 *$ & $0.1045 *$ \\
\hline $\mathrm{IL}$ & 80 & $9.7572 *$ & 0.9630 & $0.1490 *$ & 0.0466 \\
\hline IL & 90 & $29.7610 *$ & $5.1016 *$ & $0.4591 *$ & $0.2774 *$ \\
\hline IN & 10 & $4.7221 *$ & $1.8526 *$ & $0.0449 *$ & $0.0441 *$ \\
\hline IN & 50 & $12.0790 *$ & -0.3684 & $0.1042 *$ & -0.0071 \\
\hline IN & 60 & $5.0586 *$ & 0.2324 & $0.0639 *$ & 0.0099 \\
\hline IN & 70 & $12.9670 *$ & $1.7575 *$ & $0.1057 *$ & $0.0567 *$ \\
\hline \multirow[t]{2}{*}{ IN } & 80 & $7.5398 *$ & $1.3834 *$ & $0.0955 *$ & $0.0598 *$ \\
\hline & & \multicolumn{2}{|c|}{ Drought Parameter } & $\beta_{\text {disqt }}^{r} \mathrm{~s}$ or & $b_{\text {disqt }}^{r}$ 's \\
\hline IL & 10 & -0.0557 & -0.0478 & -0.0024 & -0.0013 \\
\hline IL & 20 & 0.2159 & 0.0239 & 0.0020 & 0.0010 \\
\hline IL & 40 & -0.4393 & $-0.4086 *$ & $-0.0066 *$ & $-0.0107 *$ \\
\hline IL & 70 & -0.1007 & -0.0051 & $-0.0067 *$ & -0.0022 \\
\hline IL & 80 & -0.1680 & $0.1393 *$ & -0.0052 & 0.0035 \\
\hline IL & 90 & $-1.2272 *$ & -0.1383 & $-0.0197 *$ & $-0.0098 *$ \\
\hline IN & 10 & -0.1981 & $-0.2277 *$ & -0.0021 & $-0.0060 *$ \\
\hline IN & 50 & $-0.4712 *$ & 0.1074 & $-0.0038 *$ & 0.0023 \\
\hline IN & 60 & -0.0228 & $0.0452 *$ & -0.0017 & $0.0008 *$ \\
\hline IN & 70 & $-0.8042 *$ & -0.0103 & $-0.0066 *$ & -0.0007 \\
\hline IN & 80 & -0.0680 & $0.1157 *$ & $-0.0024 *$ & $0.0018 *$ \\
\hline
\end{tabular}

Note: Asterisk (*) denotes estimates significant at 5\%. 
Table 11. F-test of Equal Coefficients

\begin{tabular}{ccccc}
\hline \hline Model & H0 & $\mathrm{F} \mathrm{Statistics}$ & $\mathrm{p}$-value & Conclusion \\
\hline Corn & $\beta_{d i}^{r}$ 's equal & $\mathrm{F}(10,95)=4.58$ & 0 & reject \\
Linear & $\beta_{d i t}^{r}$ 's equal & $\mathrm{F}(10,95)=7.51$ & 0 & reject \\
& $\beta_{d i s q}^{r}$ 's equal & $\mathrm{F}(10,95)=4.57$ & 0 & reject \\
& $\beta_{d i s q t}^{r}$ 's equal & $\mathrm{F}(10,95)=6.25$ & 0 & reject \\
Corn & $b_{d i}^{r}$ 's equal & $\mathrm{F}(10,95)=7.21$ & 0 & reject \\
Log-Linear & $b_{d i t}^{r}$ 's equal & $\mathrm{F}(10,95)=7.12$ & 0 & reject \\
& $b_{d i s q}^{r}$ 's equal & $\mathrm{F}(10,95)=6.12$ & 0 & reject \\
& $b_{d i s q t}^{r}$ 's equal & $\mathrm{F}(10,95)=6.42$ & 0 & reject \\
Soybean & $\beta_{d i}^{r}$ 's equal & $\mathrm{F}(10,95)=6.14$ & 0 & reject \\
Linear & $\beta_{d i t}^{r}$ 's equal & $\mathrm{F}(10,95)=16.62$ & 0 & reject \\
& $\beta_{d i s q}^{r}$ 's equal & $\mathrm{F}(10,95)=5.82$ & 0 & reject \\
& $\beta_{d i s q t}^{r}$,'s equal & $\mathrm{F}(10,95)=11.88$ & 0 & reject \\
Soybean & $b_{d i}^{r}$ 's equal & $\mathrm{F}(10,95)=8.22$ & 0 & reject \\
Log- Linear & $b_{d i t}^{r}$ 's equal & $\mathrm{F}(10,95)=10.45$ & 0 & reject \\
& $b_{d i s q}^{r}$ 's equal & $\mathrm{F}(10,95)=5.52$ & 0 & reject \\
& $b_{d i s q t}^{r}$ 's equal & $\mathrm{F}(10,95)=7.04$ & 0 & reject \\
\hline \hline
\end{tabular}

Table 12. Model Selection Based on Bayesian Information Criterion (BIC)

\begin{tabular}{ll}
\hline \hline Model & BIC \\
\hline Corn Linear CRD-specific Model & 21278.5 \\
Corn Linear Aggregate Model & 21065.4 \\
Corn Log-Linear CRD-specific Model & -2524.8 \\
Corn Log-Linear Aggregate Model & -2621.5 \\
Soybean Linear CRD-specific Model & 14950.9 \\
Soybean Linear Aggregate Model & 14844.0 \\
Soybean Log-Linear CRD-specific Model & -3302.0 \\
Soybean Log-Linear Aggregate Model & -3320.6 \\
\hline \hline
\end{tabular}

Table 13. Premium Rates for Corn

\begin{tabular}{cccccccc}
\hline \hline State & County & $\begin{array}{c}\text { GRP } \\
2008\end{array}$ & $\begin{array}{c}\text { GRP Drought } \\
\text { Rates }\end{array}$ & $\begin{array}{c}\text { Drought } \\
\text { Percent }\end{array}$ & $\begin{array}{c}\text { Simulated } \\
\text { GRP 2010 }\end{array}$ & $\begin{array}{c}\text { Simulated } \\
\text { GRP 2015 }\end{array}$ & $\begin{array}{c}\text { Simulated } \\
\text { GRP 2020 }\end{array}$ \\
\hline Illinois & Bureau & $2.24 \%$ & $2.39 \%$ & $92 \%$ & $0.95 \%$ & $0.77 \%$ & $0.65 \%$ \\
& & & & & $1.41 \%$ & $1.14 \%$ & $1.15 \%$ \\
Illinois & Peoria & $3.41 \%$ & $3.66 \%$ & $89 \%$ & $0.91 \%$ & $0.66 \%$ & $0.44 \%$ \\
& & & & & $1.08 \%$ & $0.61 \%$ & $0.16 \%$ \\
Indiana & \multirow{2}{*}{ Clinton } & \multirow{2}{*}{$3.21 \%$} & $2.99 \%$ & $95 \%$ & $1.43 \%$ & $1.25 \%$ & $1.08 \%$ \\
& & & & & $1.77 \%$ & $1.44 \%$ & $1.10 \%$ \\
Indiana & \multirow{2}{*}{ Spencer } & $3.61 \%$ & $2.84 \%$ & $76 \%$ & $1.62 \%$ & $1.27 \%$ & $0.98 \%$ \\
& & & & & $1.31 \%$ & $0.91 \%$ & $0.65 \%$ \\
\hline \hline
\end{tabular}


Table 14. Premium Rates for Soybeans

\begin{tabular}{cccccccc}
\hline \hline State & County & $\begin{array}{c}\text { GRP } \\
2008\end{array}$ & $\begin{array}{c}\text { GRP Drought } \\
\text { Rates }\end{array}$ & $\begin{array}{c}\text { Drought } \\
\text { Percent }\end{array}$ & $\begin{array}{c}\text { Simulated } \\
\text { GRP 2010 }\end{array}$ & $\begin{array}{c}\text { Simulated } \\
\text { GRP 2015 }\end{array}$ & $\begin{array}{c}\text { Simulated } \\
\text { GRP 2020 }\end{array}$ \\
\hline Illinois & La Salle & $2.23 \%$ & $1.16 \%$ & $65 \%$ & $0.58 \%$ & $0.53 \%$ & $0.49 \%$ \\
& & & & & $0.68 \%$ & $0.58 \%$ & $0.49 \%$ \\
Indiana & \multirow{2}{*}{ Jasper } & $2.22 \%$ & \multirow{2}{*}{$1.32 \%$} & $55 \%$ & $0.70 \%$ & $0.60 \%$ & $0.51 \%$ \\
& & & & & $0.90 \%$ & $0.77 \%$ & $0.64 \%$ \\
Indiana & \multirow{2}{*}{ Randolph } & \multirow{2}{*}{$2.58 \%$} & \multirow{2}{*}{$1.88 \%$} & \multirow{2}{*}{$76 \%$} & $0.82 \%$ & $0.73 \%$ & $0.64 \%$ \\
& & & & & $0.96 \%$ & $0.86 \%$ & $0.76 \%$ \\
Indiana & \multirow{2}{*}{ Spencer } & \multirow{2}{*}{$2.64 \%$} & \multirow{2}{*}{$2.69 \%$} & \multirow{2}{*}{$81 \%$} & $0.95 \%$ & $0.81 \%$ & $0.69 \%$ \\
& & & & & $0.81 \%$ & $0.70 \%$ & $0.59 \%$ \\
\hline \hline
\end{tabular}

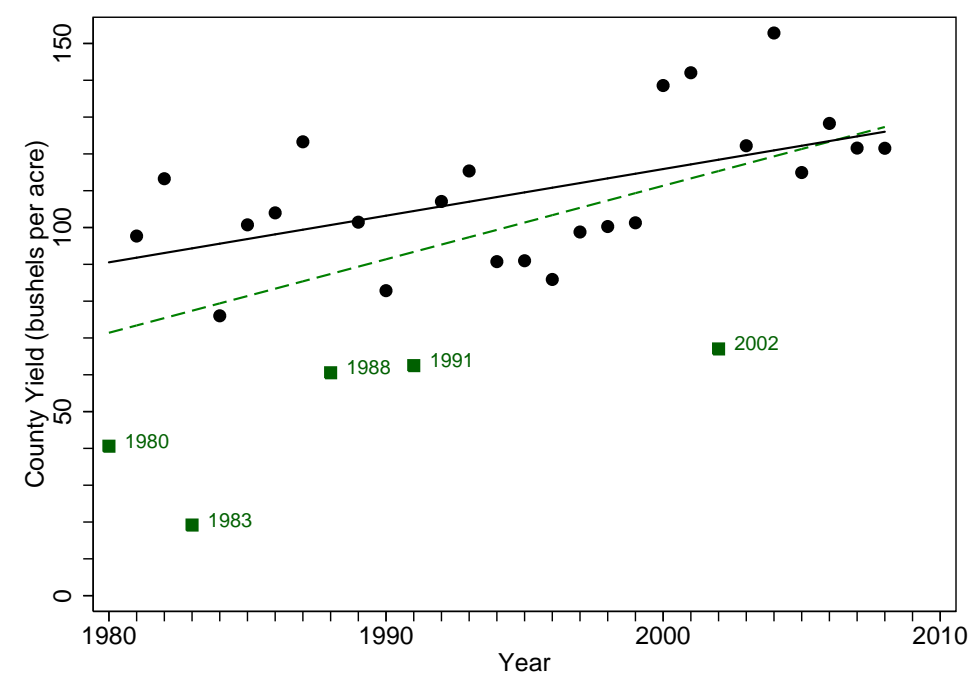

Figure 1. Corn yields of Clay County, Illinois 


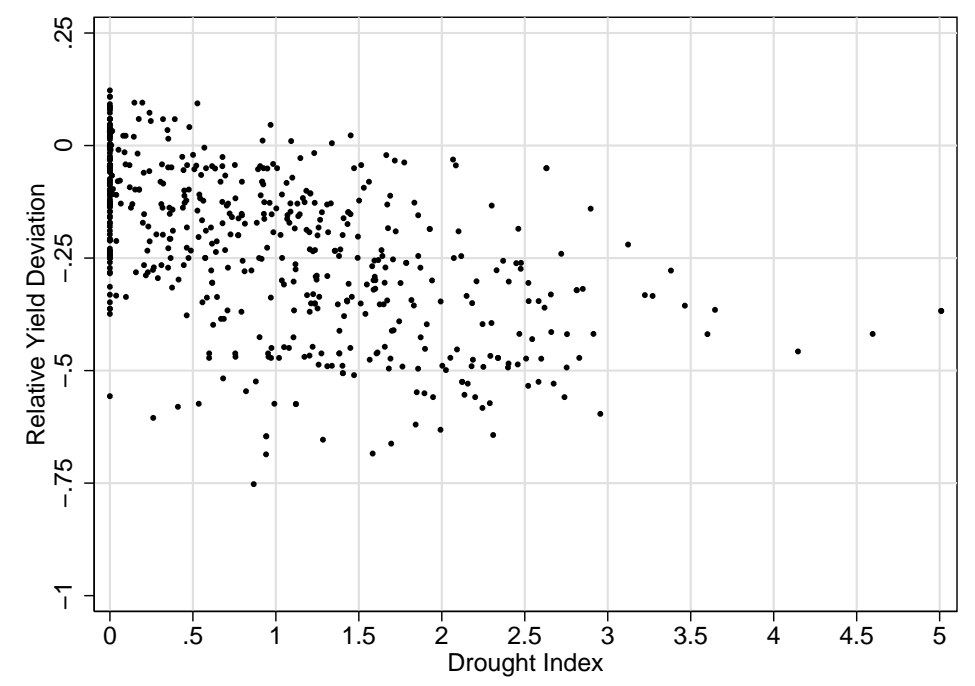

Figure 2. Relationship between the drought index and relative yield deviation

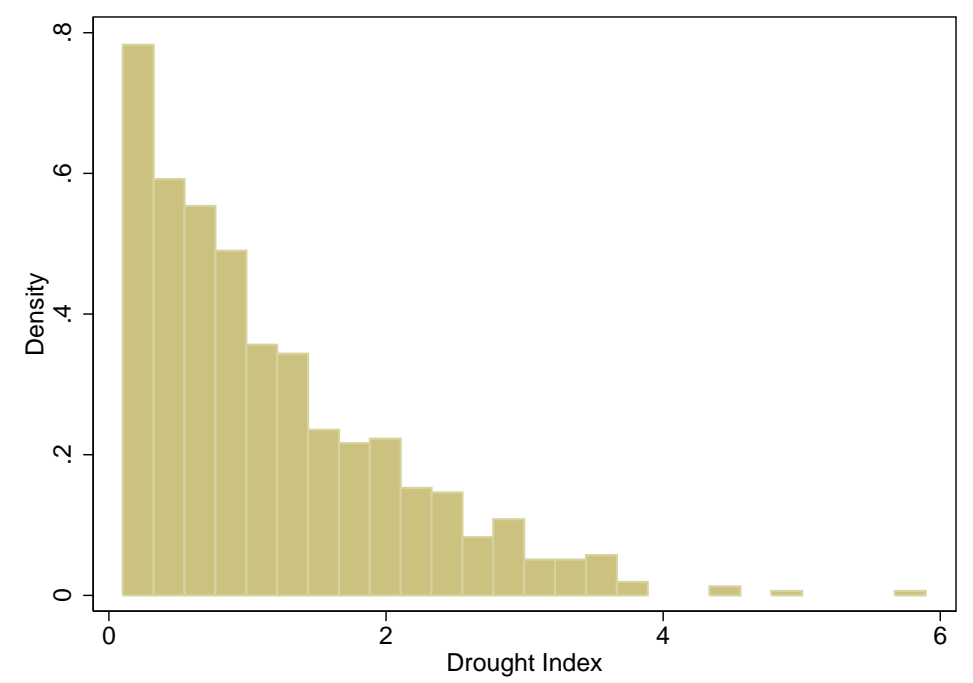

Figure 3. Histogram of drought indices in the $11 \mathrm{CRDs}$ in IL and IN truncated below .1 

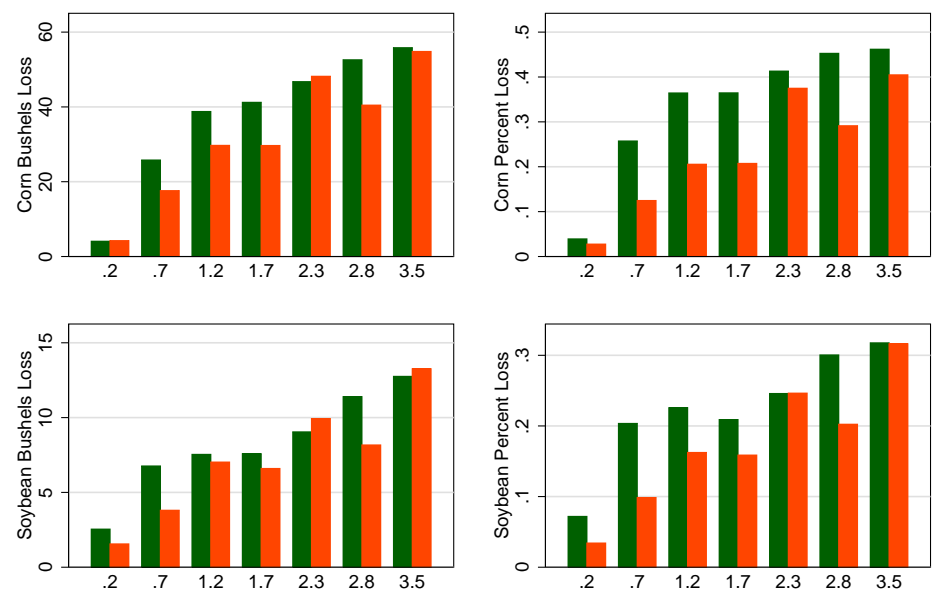

\begin{tabular}{|l|l|}
\hline $1980-1989$ & $2000-2008$ \\
\hline
\end{tabular}

Figure 4. Crop losses and drought indices
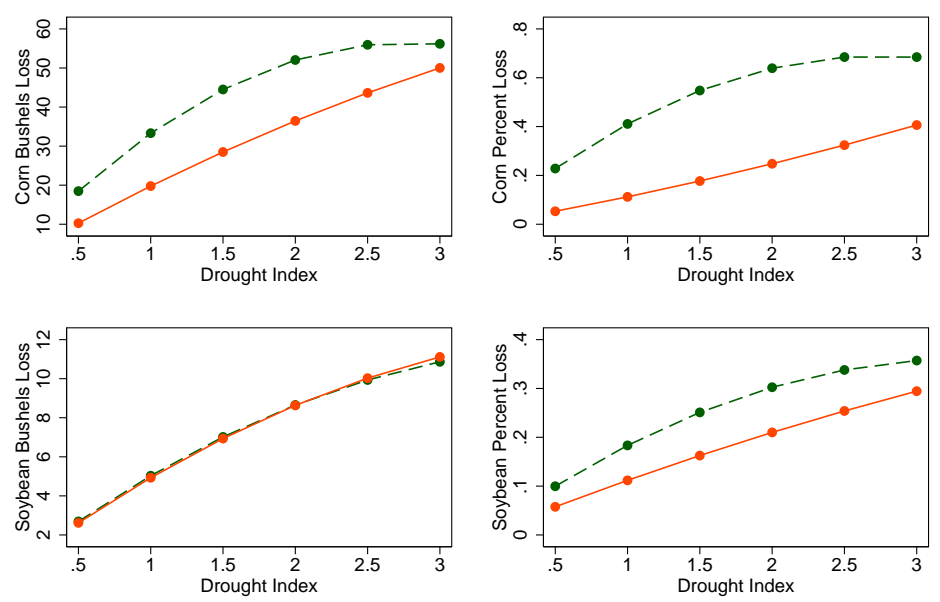

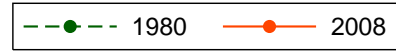

Figure 5. Model-predicted drought-induced crop losses 